\title{
A Super Wideband Directional Compact Vivaldi Antenna for Lower 5G and Satellite Applications
}

\author{
Liton Chandra Paul (iD) and Md. Mohiminul Islam \\ Dept. of Electrical, Electronic and Communication Engineering, Pabna University of Science and Technology, Pabna-6600, \\ Bangladesh \\ Correspondence should be addressed to Liton Chandra Paul; litonpaulete@gmail.com
}

Received 30 July 2021; Revised 21 October 2021; Accepted 1 November 2021; Published 29 November 2021

Academic Editor: Ahmed Toaha Mobashsher

Copyright (C) 2021 Liton Chandra Paul and Md. Mohiminul Islam. This is an open access article distributed under the Creative Commons Attribution License, which permits unrestricted use, distribution, and reproduction in any medium, provided the original work is properly cited.

\begin{abstract}
In this paper, a super wide band (SWB) Vivaldi antenna has been proposed for lower 5G bands in Sub-6 GHz and satellite applications ( $\mathrm{S}, \mathrm{C}, \mathrm{X}, \mathrm{Ku}$, and $\mathrm{K}$ band) using various performance improvement techniques. In the presented Vivaldi antenna, different slots are applied not only to increase the gain and directivity but also to get operating frequency at the intended specific frequency range. All dimensions of those slots were chosen by using the sweep parameter method. Ten corrugated side slots, two circular slots, and one via have been used to enhance the performance especially bandwidth and gain of the antenna. At the edge of wireless communication, we want to enhance two key aspects within the communication systems: the quality of service and the cost. The proposed antenna incorporates a simple structure and small size with dimensions of $45 \times 35 \times 0.79 \mathrm{~mm}^{3}$. Thus, after design, optimization, and simulation, the antenna produces a good reflection coefficient over the very large operating bandwidth of $23.19 \mathrm{GHz}, 1<\mathrm{VSWR}<2$, maximum gain of $10.2 \mathrm{dBi}$, and average radiation efficiency of above $90 \%$, which can be recommended as a suitable antenna for lower $5 \mathrm{G}$ as well as satellite applications. The antenna is designed, simulated, and analyzed by using computer simulation technology microwave studio (CST-MWS). Finally, the performance of the Vivaldi antenna has been validated by FEKO and HFSS software, and we achieved a very good matching among the results.
\end{abstract}

\section{Introduction}

Since the first Vivaldi antenna was proposed in 1979 by Gibson [1], it is widely used in ultrawideband applications such as wireless communication, biomedical detection, Radar, Satellite communication system, and so on [2]. A Vivaldi antenna is a planar broadband antenna that is made of a dielectric substrate metalized on both sides. The fedline encircles the microstrip line, terminated with a sectorshaped area that encircles the circular space. The radiating energy at the resonant points reaches over exponential patterns through the symmetrical slot lines [3]. The Vivaldi antennas are categorized into three types: tapered slot Vivaldi antenna (TSVA), antipodal Vivaldi antenna (AVA), and balanced antipodal Vivaldi antenna (BAVA). The authors in [4-6] discussed the different parameter variation of the Vivaldi antenna both analytically and experimentally. In today's life, it is inevitable to have very high speed data exchanging channels for wideband applications. A Vivaldi antenna can produce ultrawideband frequencies with high directivity and stable radiation pattern. There are several advantages of using a Vivaldi antenna such as broadband characteristics, simple structure, small size, and easy manufacturing. In [7], an ultrawideband patch antenna with a U-shaped slot on the radiating patch is introduced for triband satellite applications. The operating frequency ranges of the proposed structure are $4.9 \mathrm{GHz}-7 \mathrm{GHz}, 7.92 \mathrm{GHz}-11.08 \mathrm{GHz}$, and $11.85 \mathrm{GHz}-15.94 \mathrm{GHz}$, and gain is varied from 2.3 to 4.5 $\mathrm{dBi}$. In [8], a novel patch antenna is proposed consisting of parasitic elements and rectangular slots on the ground plane. The proposed structure has a dimension of $16 \times 8 \mathrm{~mm}^{2}$. The antenna shows the bandwidth of $11.34-17.46 \mathrm{GHz}$ and gain of $4.92-6.30 \mathrm{dBi}$. A pair of 
square-shaped slotted Vivaldi antenna with dimension of $110 \times 80 \mathrm{~mm}^{2}$ has been proposed in [9]. Its operating frequency range is $2 \mathrm{GHz}-11 \mathrm{GHz}$ and has maximum gain of $10 \mathrm{dBi}$. To enhance the performance of the traditional Vivaldi antenna, the side-slotted Vivaldi antenna (SSVA) for imaging application is proposed in [10]. It has a size of $45 \times 37 \mathrm{~mm}^{2}$ and covers an ultrawideband frequency range. It possesses a maximum gain of $6.8 \mathrm{dBi}$ and radiation efficiency is about $88 \%$. To detect brain tumor within the human head, a coplanar feed ultrawide band Vivaldi antenna is proposed in $[11,12]$, which has a dimension of $30 \times 30 \mathrm{~mm}^{2}$ and operated at a bandwidth of $3.1 \mathrm{GHz}-10.6 \mathrm{GHz}$. The gain and directivity are improved by applying corrugated slots in both sides and gratings in front of the proposed antenna. A monopole Vivaldi antenna for cellular communication including LTE, GSM, UMTS, WiMAX, and WiFi bands has been simulated and presented in [13]. The novel compact broadband monopole Vivaldi antenna has been fabricated in [14]. The size of the final prototype is $73 \times 69 \mathrm{~mm}^{2}$. In [15], an ultrawideband novel Vivaldi antenna for mobile communication application with pattern diversity has been proposed and fabricated. It covers $0.7-2.7 \mathrm{GHz}$. The huge bandwidth and high gain have been achieved by the designed antenna [16]. The operating frequency is $2.5-57 \mathrm{GHz}$ and gain is $16 \mathrm{dBi}$. To get a huge bandwidth, a comparatively larger size of antenna is opted. It results higher VSWR $(<3)$. A fern leaf inspired fractal structure has been introduced for UWB applications in [17]. In [18], the folding technique is applied on the tapered slot antenna, which shows the peak gain of $15 \mathrm{dBi}$ with a balance radiation pattern to the whole operating range. In another technique, a number of metamaterial structures have been presented to improve the directional property of conventional antenna by reducing side lobe [19]. A miniaturized AVA with slits and dielectric lens has been fabricated in [20], which operated at a bandwidth of 1-30 GHz. In [21], a flexible UWB Vivaldi antenna with $3 \mathrm{D}$-phase adjusting unit has been proposed which has better gain and pattern diversity. It has a dimension of $68 \times 52 \mathrm{~mm}^{2}$ and covers $6-18 \mathrm{GHz}$. Many other different techniques have been applied to increase antenna performance such as slotting technique, directors, patches, and lens loading technique. The antenna is fabricated by dielectric material of Rogers 5880 with a thickness of 20 mil. After analyzing the newly revealed Vivaldi antennas from [22-28], the basic motive is to decrease the size of the antenna as well as step up the higher operating bandwidth, gain, and efficiency.

During the design process of an ultra wideband Vivaldi antenna, one faces many challenges. One of them is the miniaturization of the antenna with wide impedance bandwidth and good radiation performance. In some cases, a low gain is exhibited through the entire ultrawide operating band. In the minimization process, reducing the size of the antenna also decreases the performance of the antenna. Therefore, developing a compact design of the directional Vivaldi antenna with good gain and directivity, better efficiency, and VSWR for satellite communication and other ultra wideband applications is a very challenging task. In this paper, a super wideband Vivaldi antenna having a huge bandwidth of $23.19 \mathrm{GHz}(3.06 \mathrm{GHz}-26.25 \mathrm{GHz})$ and compact size of $45 \times 35 \times 0.79 \mathrm{~mm}^{3}$ has been presented and discussed briefly. The main achievement of this research work is to develop a compact and super wide band Vivaldi antenna without compromising stability of gain and high radiation efficiency.

\section{Tapered Slot Vivaldi Antenna Geometry}

The geometrical structure of a microstrip line fed tapered slot super wideband compact Vivaldi antenna is described in this section. It is an exponential double-sided corrugated tapered slot Vivaldi antenna. The total design processes have been presented in five steps. Figure 1(a) represents a simple tapered Vivaldi aerial which is the first step of our proposed antenna. Two exponential tapered slots are placed symmetrically on the top of the substrate. Rogers RT 5880 dielectric material has been used as substrate of the antenna, having a relative permittivity of 2.2 , tangent loss of 0.0009 , and thickness of $0.79 \mathrm{~mm}$. The microstrip line feeding is used as a feeding technique, which connects the two exponential tapered slots. The overall dimension $(L \times W)$ of the Vivaldi antenna is $45 \mathrm{~mm} \times 35 \mathrm{~mm}$. The thickness of the copper plate which is used as a radiating patch is $0.035 \mathrm{~mm}$. The exponential profile of the designed Vivaldi antenna can be described by the following equation [11]:

$$
x=C_{1} e^{R z}+C_{2}
$$

where

$$
\begin{aligned}
& C_{1}=\frac{x_{2}-x_{1}}{e^{R z_{2}}-e^{R z_{1}}}, \\
& C_{2}=\frac{x_{2} e^{R z_{2}}-x_{1} e^{R z_{1}}}{e^{R z_{2}}-e^{R z_{1}}} .
\end{aligned}
$$

Here, the points $\left(x_{1}, z_{1}\right)$ and $\left(x_{2}, z_{2}\right)$ are the endpoints of the flare. In this case, the taper rate is 0.135 which results in a wide mouth opening of $25.34 \mathrm{~mm}$ at the upper edge between the flares. At the second step, four corrugated slots are created in the top two sides of the metallic plates, which are shown in Figure 1(b). Each flare has two corrugated slots. The width of the slots is $2 \mathrm{~mm}$. The lengths of the slots are $4 \mathrm{~mm}$ and $4.5 \mathrm{~mm}$. In the third step, similarly additional six corrugated slots are made with the previous four slots and optimized the dimensions of the corrugated slots to ensure better performance than previous steps. The dimensions of the slots are $5 \mathrm{~mm}$ and $5.5 \mathrm{~mm}$. The described structure of the antenna is presented in Figure 1(c). Two identical circular slots having a radius of $5 \mathrm{~mm}$ are added at the fourth step. The tapered slot Vivaldi antenna with all corrugated and circular slots is shown in Figure 1(d).

All the slots including corrugated slots make the antenna ultrawideband and enhance gain as well as increase the efficiency than previous steps. And finally, a shorting pin named via has been used which makes direct connection between the feed line and metal flare. This via promotes the antennas bandwidth from ultrawideband to super wideband. 


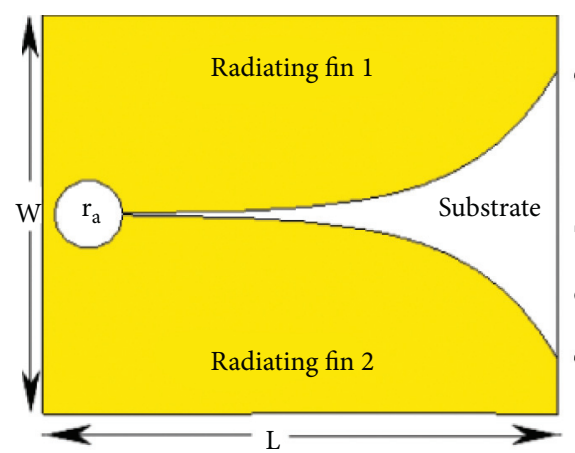

(a)

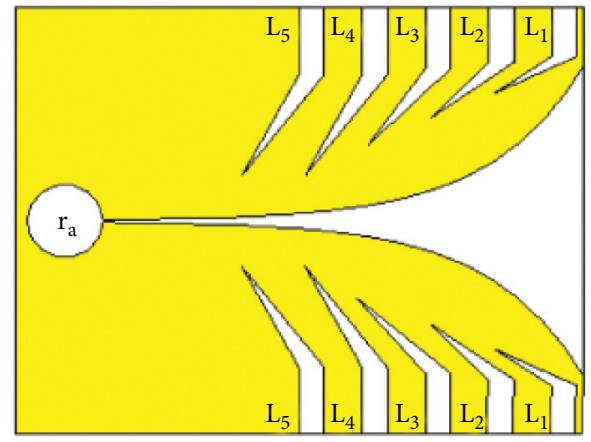

(c)

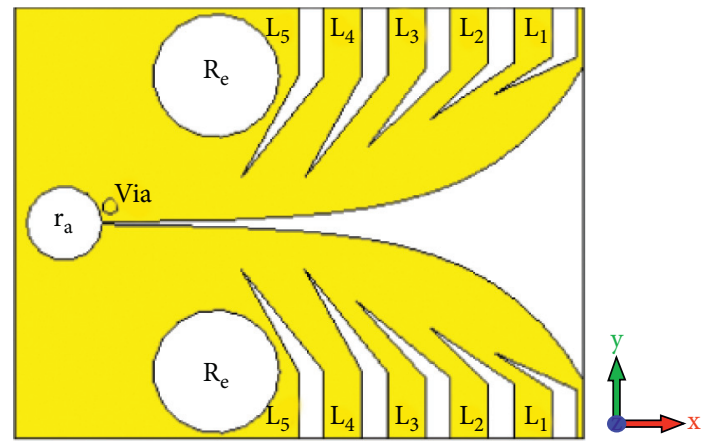

(e)

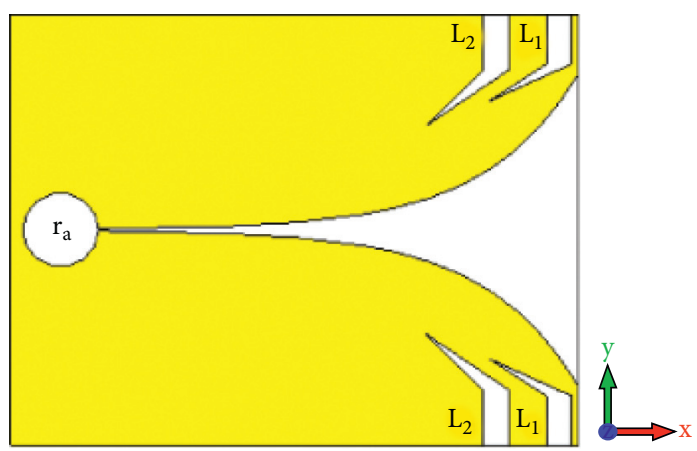

(b)

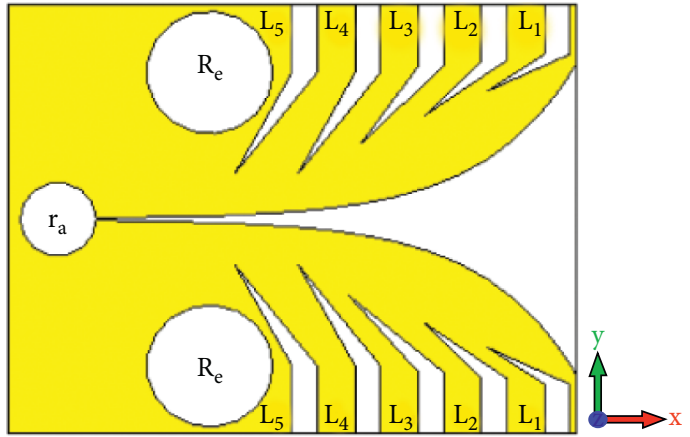

(d)

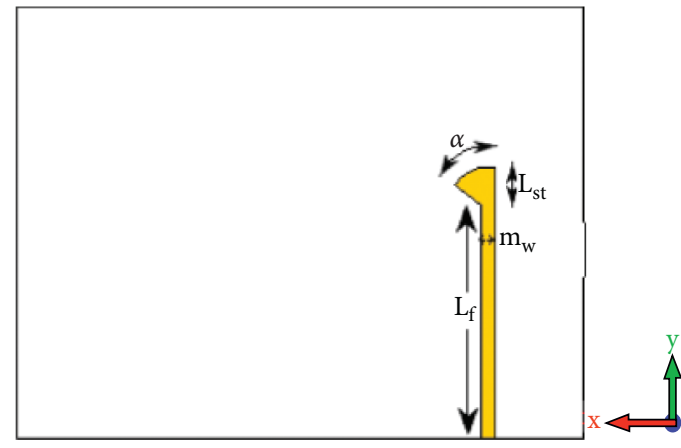

(f)

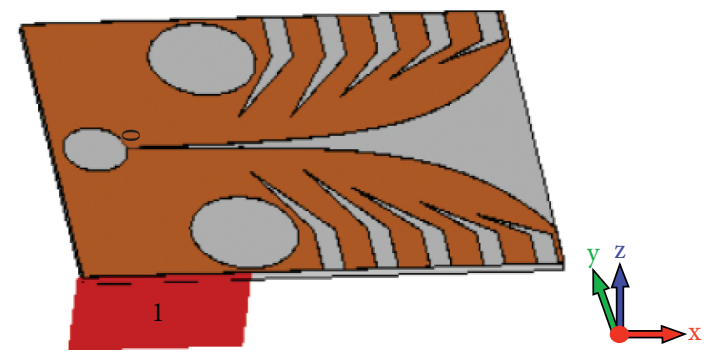

(g)

Figure 1: Evolution process of the proposed Vivaldi antenna: (a) Step 1 (front view); (b) Step 2 (front view); (c) Step 3 (front view); (d) Step 4 (front view); (e) Step 5 (front view) (proposed); (f) back view; (g) 3D view of the proposed antenna.

The via also enhances the surface current distribution throughout the antenna. The metal via has a height of $0.86 \mathrm{~mm}$ and radius of $0.6 \mathrm{~mm}$ as shown in Figure 1(e). Figure 1(f) shows the structure of the microstrip line feed of the proposed Vivaldi antenna. After applying all different techniques (like corrugated both sided slots, circular slots, and via) to enhance the antenna performance and using sweep parameters process, finally a super wideband compact tapered slot Vivaldi antenna has been proposed whose $3 \mathrm{D}$ view with port is depicted in Figure $1(\mathrm{~g})$. The geometrical parameters of the proposed SWB Vivaldi antenna are listed in Table 1. 


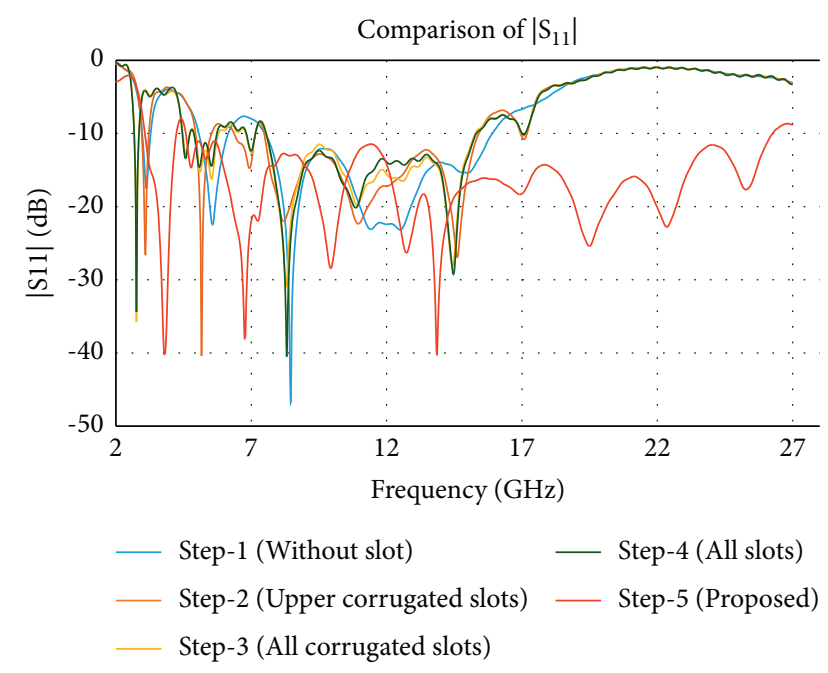

FIgURe 2: Return loss curve for different evolution stages.

TABle 1: Geometrical parameters of the proposed tapered slot super wideband vivaldi antenna.

\begin{tabular}{lc}
\hline Parameter with symbol & Value $(\mathrm{mm})$ \\
\hline Length of antenna, $L$ & 45 \\
Width of antenna, $W$ & 35 \\
Height of substrate, $h$ & 0.79 \\
Thickness of patch, $m_{\mathrm{t}}$ & 0.035 \\
Width of microstrip feed line, $m_{\mathrm{w}}$ & 1.2 \\
Tapper rate, $r$ & 0.135 \\
Throat width, $s$ & 0.05 \\
Back wall offset, ext & 1 \\
Radius of cavity, $r_{a}$ & 3 \\
Port coefficient, $k$ & 9.53 \\
Dielectric constant of substrate, $\varepsilon_{r}$ & 2.2 \\
Tangent loss of substrate, $\delta$ & 0.0009 \\
Angle of radial stub, $a$ & $70 \mathrm{deg}$ \\
Length of the radial stub, $L_{\mathrm{st}}$ & 4.5 \\
Outer mouth opening, $W_{\mathrm{o}}$ & 25.34 \\
Radius of circular slots, $R_{c}$ & 5 \\
Distance of via from the slot, te & 1.4 \\
\hline
\end{tabular}

\section{Results and Performance Estimation}

This section describes all the results and analysis of the proposed Vivaldi antenna that is presented in previous sections. Initially, the proposed Vivaldi antenna is analyzed and optimized using 3D EM simulator software named CST microwave studio. At the end, the obtained results are also verified by other two professional softwares: FEKO and HFSS. A comparison of the $S_{11}$ curves from Step 1 to Step 5 is depicted in Figure 2 to understand the successive bandwidth improvement after applying different aforementioned techniques on the designed SWB Vivaldi antenna. It can be easily noted that no other steps except Step 5 has operating bandwidth after $16 \mathrm{GHz}$, and only for Step 5, it holds up to $26.25 \mathrm{GHz}$. So, Step 5 has a larger bandwidth than the previous four steps. In this case, the metal via has a great influence on extending the UWB to SWB and also improves the current distribution of the antenna. The final Step 5 also provides much better return loss than any others. The antenna possesses the maximum return loss of $-40.322 \mathrm{~dB}$ at $13.86 \mathrm{GHz}$.
Figure 3 illustrates the gain of the five consecutive steps of this presented work. The average gain of the proposed antenna is above $8 \mathrm{dBi}$ through the whole operating super wideband ranging from $3.06 \mathrm{GHz}$ to $26.25 \mathrm{GHz}$. The comparison of radiation efficiency between Step 1 to Step 5 is shown in Figure 4. The maximum radiation efficiency of the proposed antenna is approximately $99 \%$, and the average is above $95 \%$. Therefore, the antenna reveals good efficacy to radiate energy. The voltage standing wave ratios of all the stages of the antenna at the frequency range of $3 \mathrm{GHz}$ to $27 \mathrm{GHz}$ are displayed in Figure 5. It is certified that the VSWR of a radiating antenna varies from 1 to 2 . For the best performance, the value tends to unity at every resonant frequency of the finally proposed compact Vivaldi antenna. It can be seen that the VSWR of the proposed antenna is 1.01, 1.02, $1.08,1.09,1.07,1.15,1.18$, and 1.25 at resonant frequencies of $3.81 \mathrm{GHz}, 6.75 \mathrm{GHz}, 10 \mathrm{GHz}, 12.4 \mathrm{GHz}, 13.86 \mathrm{GHz}, 19.5 \mathrm{GHz}$, $22.5 \mathrm{GHz}$, and $25.5 \mathrm{GHz}$, respectively. Figure 6 depicts the 3D view of gain for the proposed antenna at major three resonant frequencies of $3.81 \mathrm{GHz}, 6.75 \mathrm{GHz}$, and $13.86 \mathrm{GHz}$. The surface current distribution of the proposed antenna is $196.184 \mathrm{~A} / \mathrm{m}, 186.8222 \mathrm{~A} / \mathrm{m}$, and $351.789 \mathrm{~A} / \mathrm{m}$ at the frequencies of $3.81 \mathrm{GHz}, 6.75 \mathrm{GHz}$, and $13.86 \mathrm{GHz}$, respectively, which are represented in Figure 7. It can also be seen that the current of the antenna is mostly spread on the radiating fins at both lower and higher frequencies, which favors to assemble the electromagnetic energy and expand the stability of radiation of the proposed SWB Vivaldi antenna. Figure 8 represents the $S_{11}$-parameter of the finally proposed SWB Vivaldi antenna from 2 to $27 \mathrm{GHz}$. It has been seen that there is a super wide operating band (SWB). The $-10 \mathrm{~dB}$ bandwidth of the antenna covers from $3.06 \mathrm{GHz}$ to $26.25 \mathrm{GHz}$. There are multiple resonant frequencies that are $3.81 \mathrm{GHz}, 6.75 \mathrm{GHz}$, $10 \mathrm{GHz}, 12.4 \mathrm{GHz}, 13.86 \mathrm{GHz}, 19.5 \mathrm{GHz}, 22.5 \mathrm{GHz}$, and $25.5 \mathrm{GHz}$. The operating band covers prescribed all the lower $5 \mathrm{G}$ bands in sub-6 GHz like in USA, $3100-3550 \mathrm{MHz}$ and $3700-4200 \mathrm{MHz}$, in Europe, $3400-3800 \mathrm{MHz}$; in Spain, 3600-3800 MHz; in China, $3300-3600 \mathrm{MHz}$, $4400-4500 \mathrm{MHz}$, and $4800-4990 \mathrm{MHz}$; in Ireland, 3.4-3.8 GHz; in Japan, 3600-4200 MHz and 4400-4900 MHz; in Korea, $3400-3700 \mathrm{MHz}$; in India $3300-3400 \mathrm{MHz}$ as well as the designed antenna also covers many satellite bands like S-band (2-4 GHz) (partial coverage), C-band (4-8 GHz), $\mathrm{X}$-band $(8-12 \mathrm{GHz}), \mathrm{Ku}$-band $(12-18 \mathrm{GHz})$, and $\mathrm{Ka}$-band $(26-40 \mathrm{GHz})$ (partial coverage). Some key performance indexes estimated by CST are listed in Table 2. The performances estimated by CST have also been buttressed and verified by redesigning with the help of other two renowned electromagnetic (EM) simulators: FEKO and HFSS. FEKO uses Method of Moments (MoM) integral formulation of Maxwell's equations where HFSS uses finite element method and CST has multiple EM simulation solvers which use methods such as finite element method (FEM), finite integration technique (FIT), and transmission line matrix method (TLM). In Figures 9-11, we have presented the estimated reflection coefficient, gain, and efficiency validation, respectively. There are very high similarity index among all the results obtained from CST, FEKO, and HFSS for the proposed antenna. 


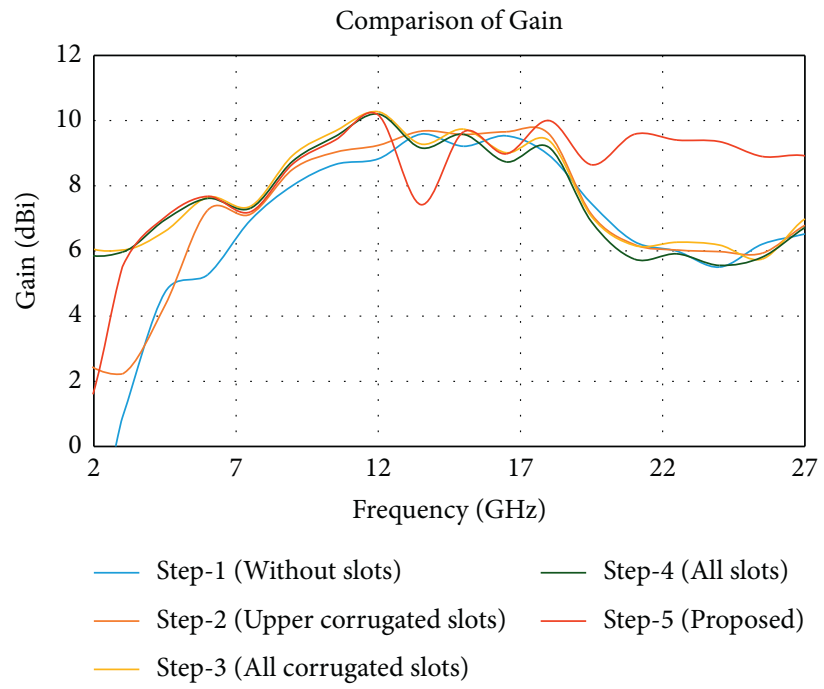

Figure 3: Gain curve for different evolution stages.

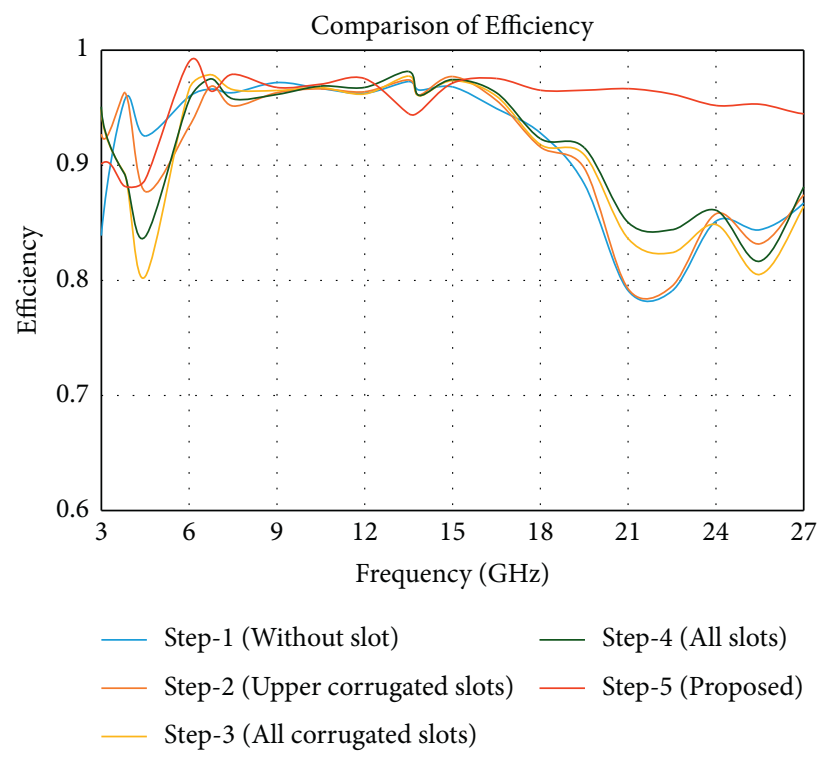

Figure 4: Efficiency curve for different evolution stages.

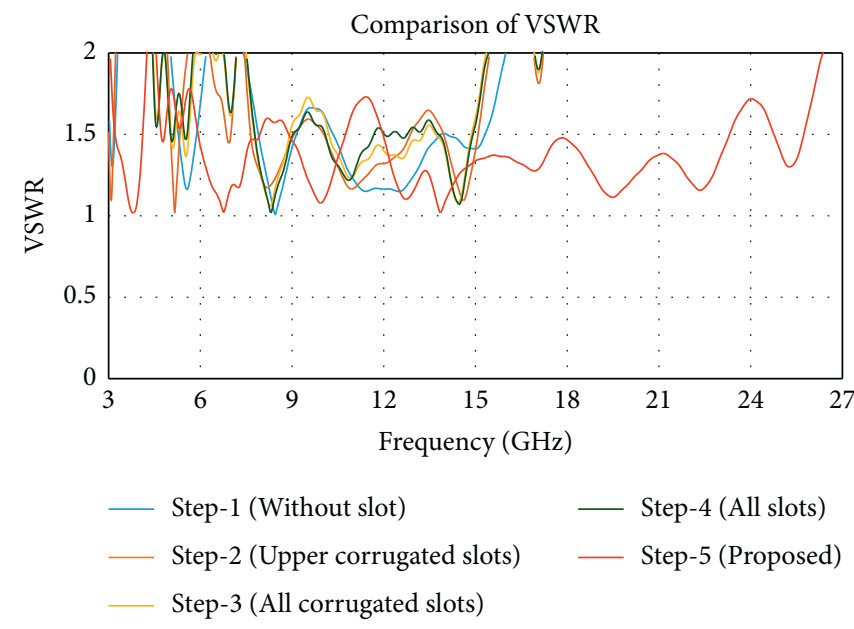

FIGURE 5: VSWR curve for different evolution stages. 


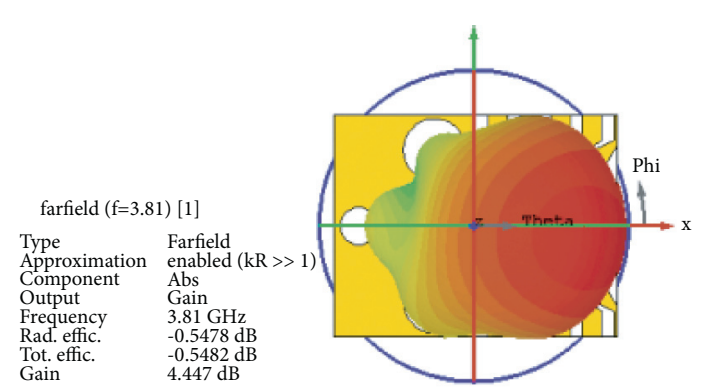

(a)

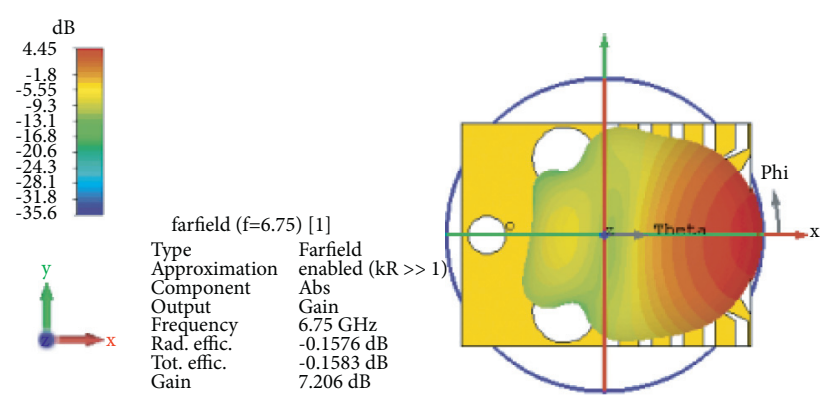

(b)
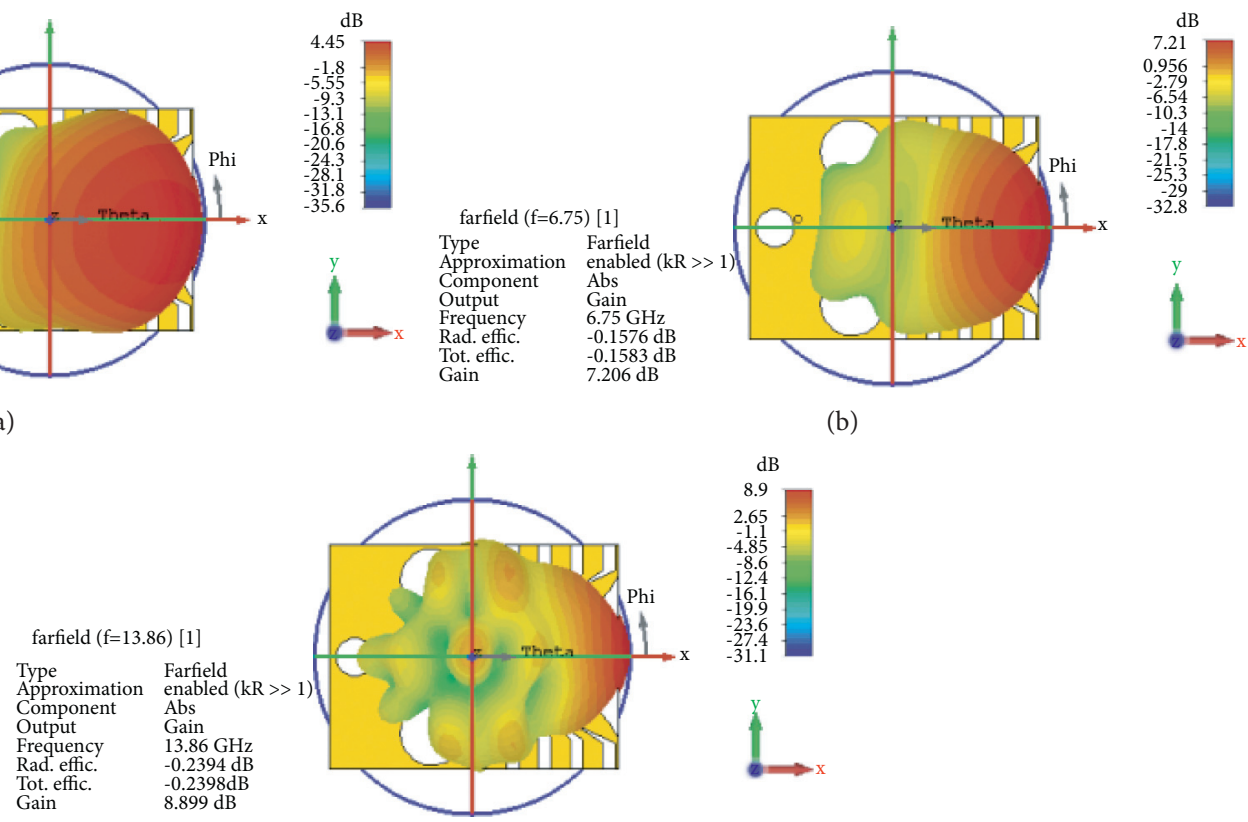

(c)

Figure 6: 3D radiation pattern at (a) $3.81 \mathrm{GHz}$, (b) $6.75 \mathrm{GHz}$, and (c) $13.86 \mathrm{GHz}$.

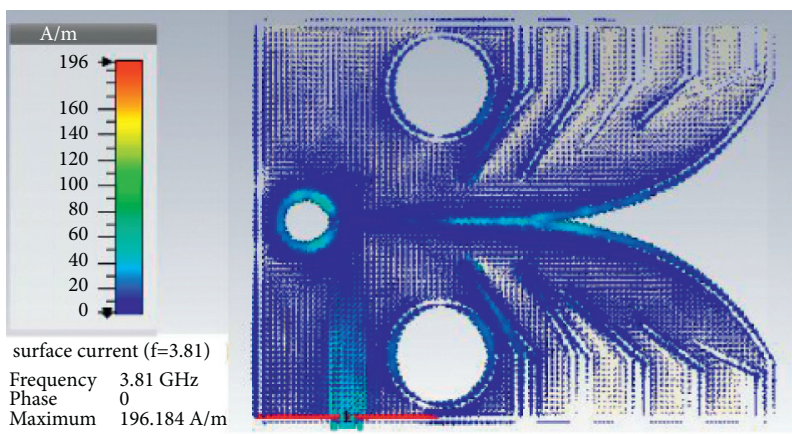

(a)

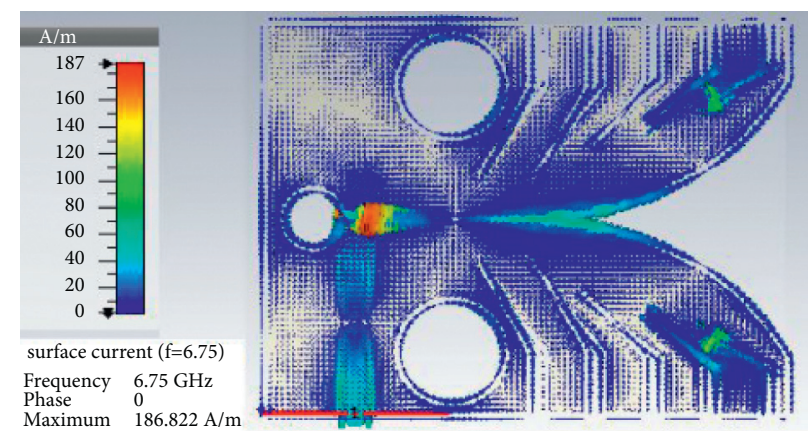

(b)
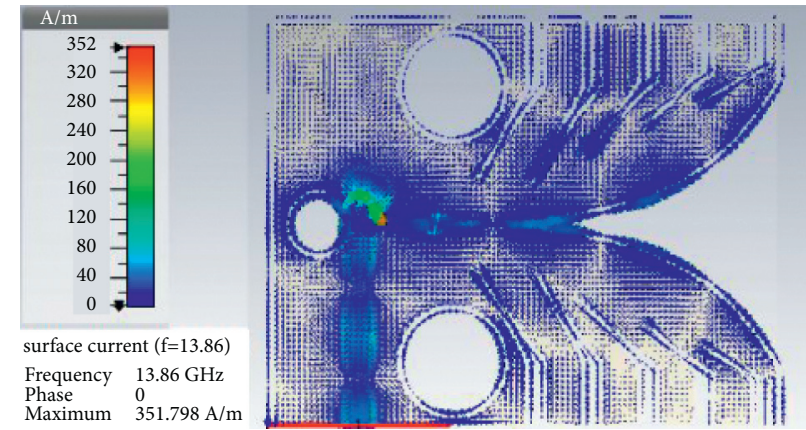

(c)

Figure 7: Surface current distribution at (a) $3.81 \mathrm{GHz}$, (b) $6.75 \mathrm{GHz}$, and (c) $13.86 \mathrm{GHz}$.

The electric fields (E-fields) for all the steps for $\mathrm{phi}=0^{\circ}$ and $90^{\circ}$ are depicted in Figure 12 at $3.81 \mathrm{GHz}, 6.75 \mathrm{GHz}$, and $13.86 \mathrm{GHz}$, respectively. For $\mathrm{phi}=0^{\circ}$ and $3.81 \mathrm{GHz}$ as presented in Figure 12(a), Step 5, i.e., the proposed antenna possesses the main lobe of $20.6 \mathrm{dBV} / \mathrm{m}$ with the angular width of $163.5^{\circ}$ where as Step 1 has the main lobe of 19.1 $\mathrm{dBV} / \mathrm{m}$ with the angular width of $24.1^{\circ}$ only. Though directions of the main lobe for the proposed antenna and Step 1 antenna are same $\left(72^{\circ}\right)$, the proposed antenna shows better main lobe magnitude $(23.6 \mathrm{dBV} / \mathrm{m})$ and wider angular width 


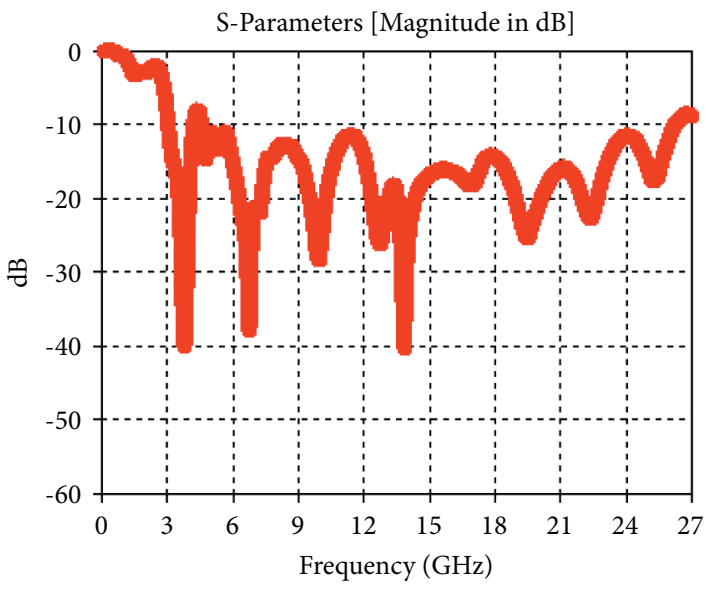

Figure 8: Return loss curve of Step 5 (proposed Vivaldi antenna).

TABLE 2: Performance metrics of the proposed super wideband Vivaldi antenna.

\begin{tabular}{lc}
\hline Name of the parameter & Value \\
\hline$-10 \mathrm{~dB}$ bandwidth $(\mathrm{GHz})$ & 23.19 \\
Lower cut off frequency $(\mathrm{GHz})$ & 3.06 \\
Higher cut off frequency $(\mathrm{GHz})$ & 26.25 \\
Return loss $(\mathrm{dB})$ at $13.86 \mathrm{GHz}$ & -40.19 \\
Max. gain $(\mathrm{dBi})$ & 10.2 \\
VSWR & $1<$ VSWR $<2$ \\
Efficiency $(\%)$ & Above 90 \\
\hline
\end{tabular}

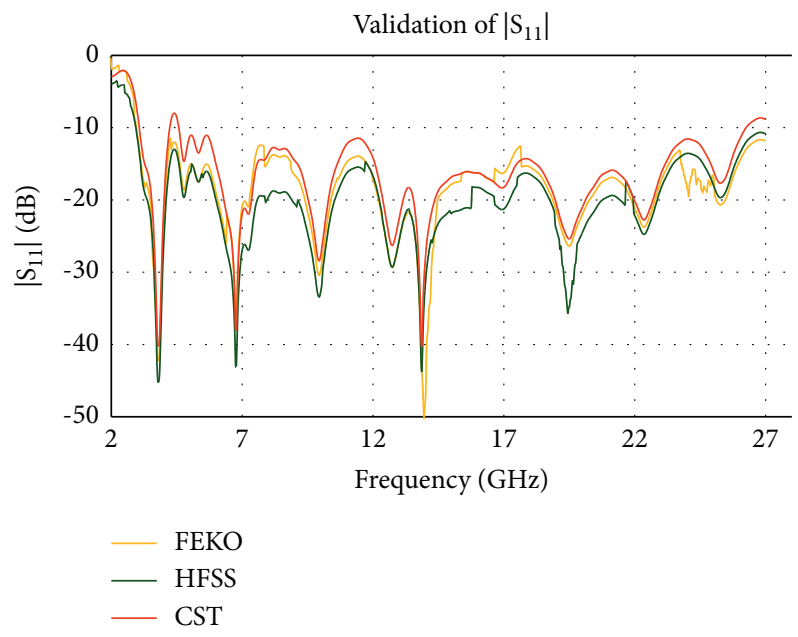

FIGURE 9: Validation of return loss curve of the proposed Vivaldi antenna.

$\left(110.7^{\circ}\right)$ as in Figure 12(b). For the proposed antenna at phi $=0$ o as shown in Figure 12(c), the main lobe direction slightly shifted from $89^{\circ}$ (Step 1) to $91^{\circ}$ at $13.86 \mathrm{GHz}$, and in this case, the side lobe label is $-7.6 \mathrm{~dB}$. In Figure 12(d), the designed antenna has a main lobe direction of $2^{\circ}$, magnitude of main lobe of $17.1 \mathrm{dBV} / \mathrm{m}$, and $3 \mathrm{~dB}$ angular width of $35.3^{\circ}$. On the other hand, as presented in Figures 12(e) and 12(f), the proposed antenna holds the magnitude of main lobe of $9.78 \mathrm{dBV} / \mathrm{m}$ and $16.3 \mathrm{dBV} / \mathrm{m}$ and $3 \mathrm{~dB}$ angular width of $28.1^{\circ}$ and $31.9^{\circ}$; directions of main lobes are $2^{\circ}$ and $4^{\circ}$ at $6.75 \mathrm{GHz}$ and $13.86 \mathrm{GHz}$, respectively.
The magnetic fields (H-fields) for all the steps of the proposed antenna are presented in Figure 13 considering different conditions. Figures 13(a)-13(c) present the $\mathrm{H}$-fields for phi $=0^{\circ}$ at $3.81 \mathrm{GHz}, 6.75 \mathrm{GHz}$, and $13.86 \mathrm{GHz}$, respectively. And Figures 13(d)-13(f) show the H-fields for phi $=90^{\circ}$. At phi $=0^{\circ}$ and $3.81 \mathrm{GHz}$ resonant frequency, the finally designed antenna shows the main lobe magnitude of $-30.9 \mathrm{dBA} / \mathrm{m}$ and main lobe direction of $136^{\circ}$. The antenna (Step 5) presents the side lobe label of $-9.4 \mathrm{~dB}$ and $-4.6 \mathrm{~dB}$ for $\mathrm{phi}=0^{\circ} ; 6.75 \mathrm{GHz}$ and $\mathrm{phi}=0^{\circ} ; 13.86 \mathrm{GHz}$. At phi $=90^{\circ}$, the proposed antenna has the main lobe 


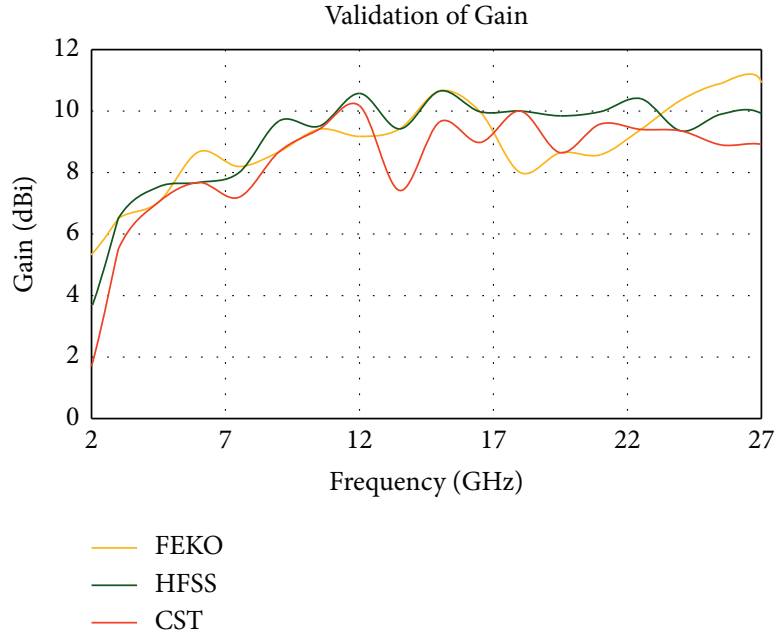

FIGURE 10: Validation of gain curve of the proposed Vivaldi antenna.

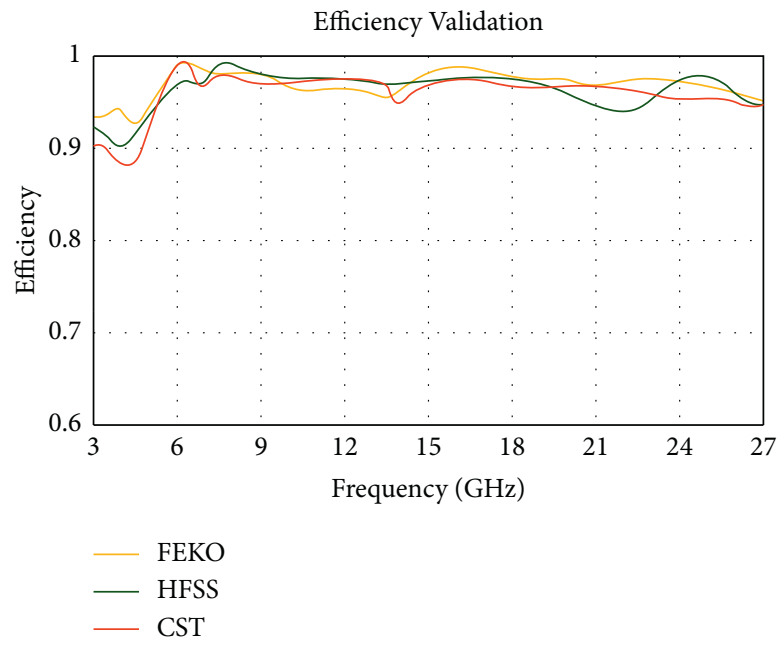

FIGURE 11: Validation of efficiency curve of the proposed Vivaldi antenna.

Farfield E-Field ( $\mathrm{r}=1 \mathrm{~m})$ Abs $(\mathrm{Phi}=0)$

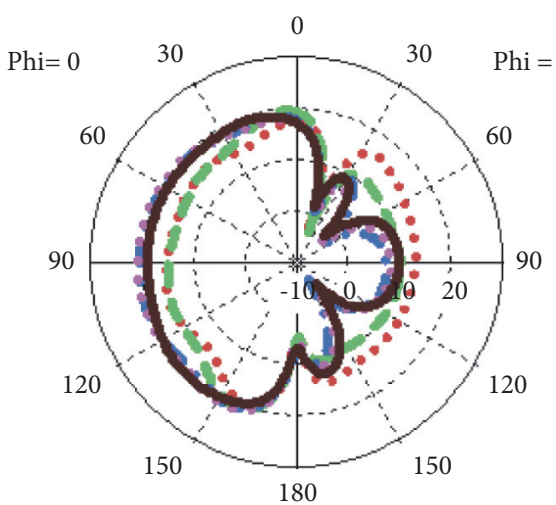

Theta/Degree vs. dBV/m

$$
\begin{array}{llll}
\ldots . & \text { Step } 1 & \ldots . & \text { Step } 4 \\
-- & \text { Step } 2 \\
-\cdot & \text { Step } 3 & & \text { Step } 5
\end{array}
$$

(a)
Farfield E-Field $(\mathrm{r}=1 \mathrm{~m})$ Abs $(\mathrm{Phi}=0)$

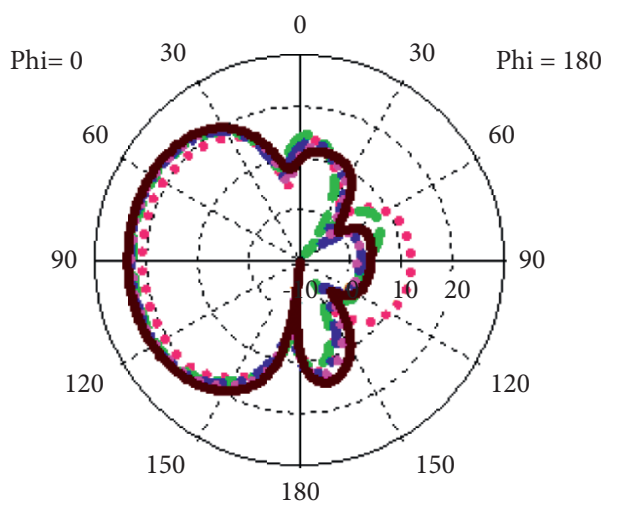

Theta/Degree vs. dBV/m

Step $1 \quad \cdots$ Step 4

- - Step $2 \quad$ Step 5

-.- Step 3 
Farfield E-Field ( $\mathrm{r}=1 \mathrm{~m})$ Abs $(\mathrm{Phi}=0)$

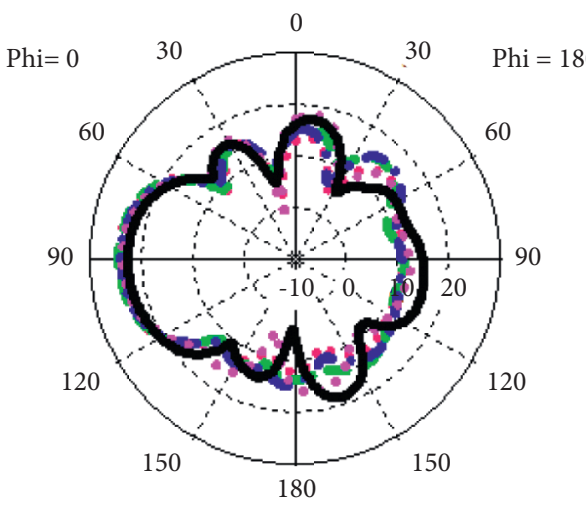

Theta/Degree vs. dBV/m

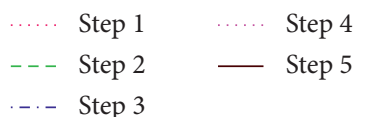

(c)

Farfield E-Field ( $\mathrm{r}=1 \mathrm{~m})$ Abs (Phi=90)

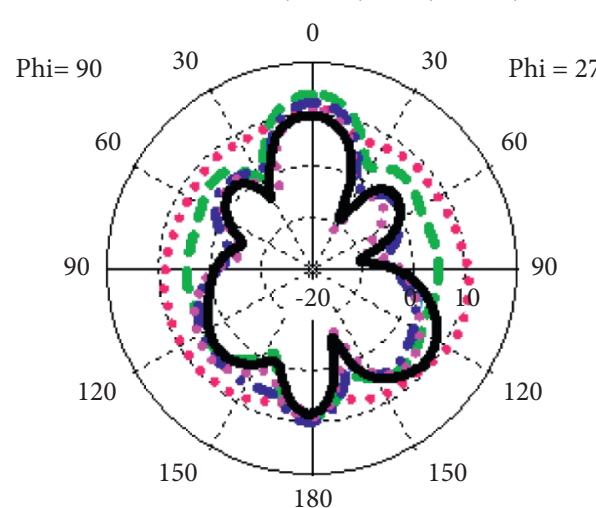

Theta/Degree vs. $\mathrm{dBV} / \mathrm{m}$

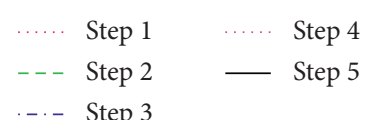

(e)
Farfield E-Field ( $\mathrm{r}=1 \mathrm{~m})$ Abs (Phi=90)

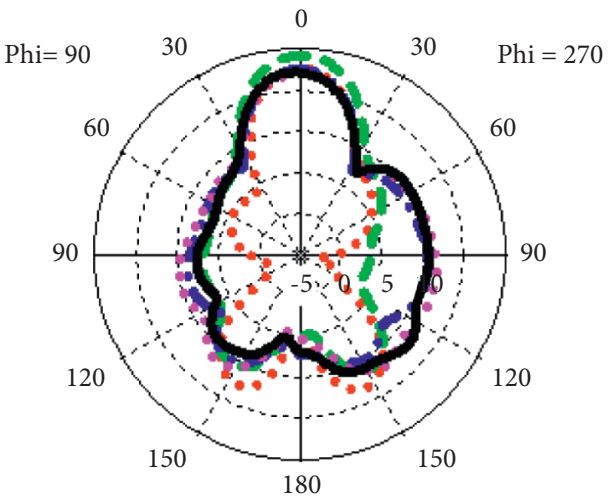

Theta/Degree vs. dBV/m

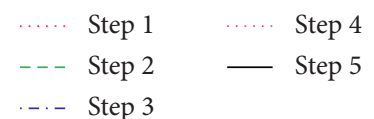

(d)

Farfield E-Field ( $\mathrm{r}=1 \mathrm{~m})$ Abs $(\mathrm{Phi}=90)$

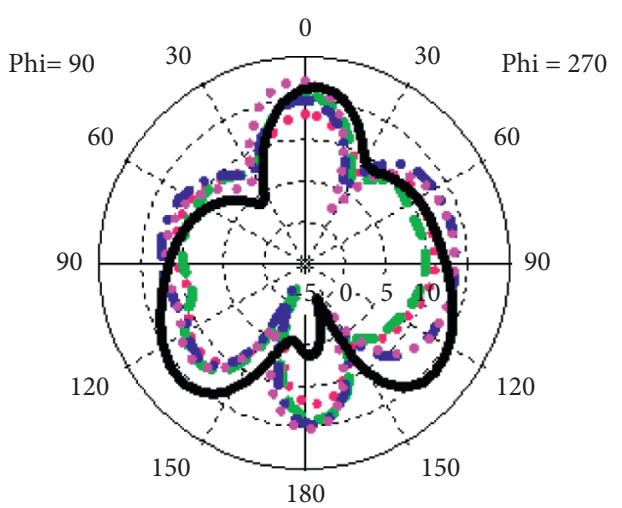

Theta/Degree vs. $\mathrm{dBV} / \mathrm{m}$

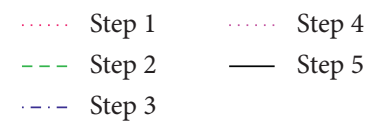

(f)

Figure 12: Electric field (E-field) for all the steps at Phi $=0^{\circ}$ and $90^{\circ}$ : (a) E-field (Phi $\left.=0^{\circ} ; 3.81 \mathrm{GHz}\right) ;(\mathrm{b}) \mathrm{E}-\mathrm{field}\left(\mathrm{Phi}=0^{\circ} ; 6.75 \mathrm{GHz}\right) ;(\mathrm{c}) \mathrm{E}-$ field $\left(\mathrm{Phi}=0^{\circ} ; 13.86 \mathrm{GHz}\right)$; (d) E-field $\left(\mathrm{Phi}=90^{\circ} ; 3.81 \mathrm{GHz}\right)$; (e) E-field (Phi $\left.=90^{\circ} ; 6.75 \mathrm{GHz}\right)$; (f) E-field $\left(\mathrm{Phi}=90^{\circ} ; 13.86 \mathrm{GHz}\right)$.

magnitude of $-34.4 \mathrm{dBA} / \mathrm{m},-41.7 \mathrm{dBA} / \mathrm{m}$, and -35.2 $\mathrm{dBA} / \mathrm{m}$, and main lobe directions are $2^{\circ}, 2^{\circ}$, and $4^{\circ}$ for $3.81 \mathrm{GHz}, 6.75 \mathrm{GHz}$, and $13.86 \mathrm{GHz}$, respectively. Table 3 shows a comparison scenario with some recently published relevant works. From the table, our proposed Vivaldi antenna has compact size compared with many other antennas and also possesses a super wide operating band covering sub-6 GHz band, S-, C-, X-, Ku-, and $\mathrm{K}$-bands of satellite applications. It also shows excellent return loss profile and maximum gain of $10.2 \mathrm{dBi}$ holding good average gain over the entire operating super wideband. 
Farfield H-Field ( $\mathrm{r}=1 \mathrm{~m})$ Abs (Phi=0)

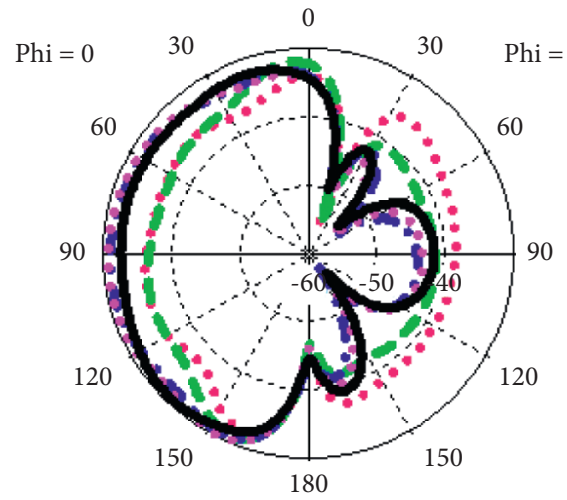

Theta/Degree vs. dBA/m

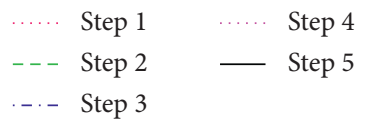

(a)

Farfield H-Field ( $\mathrm{r}=1 \mathrm{~m})$ Abs $(\mathrm{Phi}=0)$

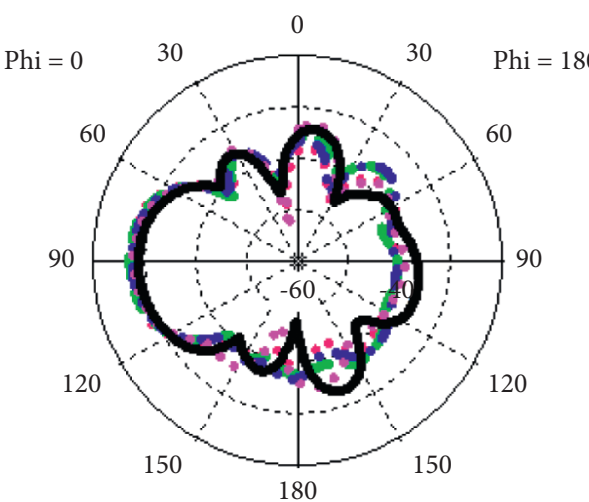

Theta/Degree vs. dBA/m

$$
\begin{array}{llll}
\ldots & \text { Step } 1 & \ldots \ldots & \text { Step } 4 \\
\ldots-- & \text { Step } 2 \\
\ldots- & \text { Step } 3 & &
\end{array}
$$

(c)

Farfield H-Field ( $\mathrm{r}=1 \mathrm{~m})$ Abs (Phi=90)

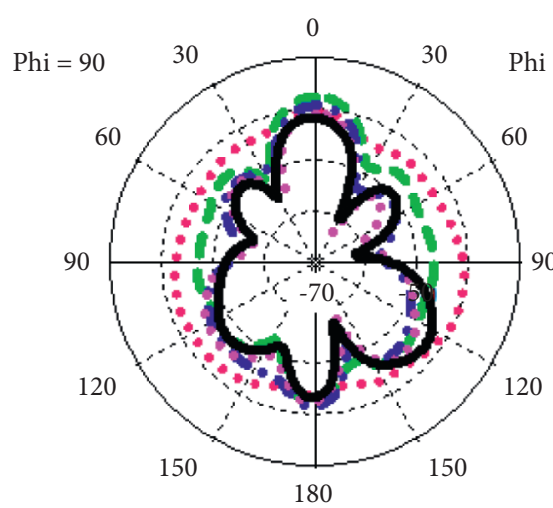

Theta/Degree vs. dBA/m

$$
\begin{array}{llll}
\ldots \ldots & \text { Step } 1 & \ldots \ldots & \text { Step } 4 \\
--- & \text { Step } 2 \\
\ldots & \text { Step } 3 & & \text { Step } 5
\end{array}
$$

(e)
Farfield H-Field ( $\mathrm{r}=1 \mathrm{~m})$ Abs $(\mathrm{Phi}=0)$

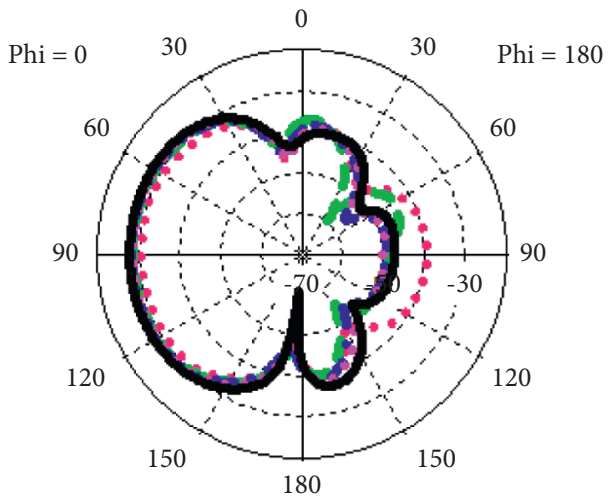

Theta/Degree vs. dBA/m

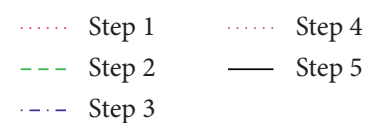

(b)

Farfield H-Field (r=1 m) Abs (Phi=90)

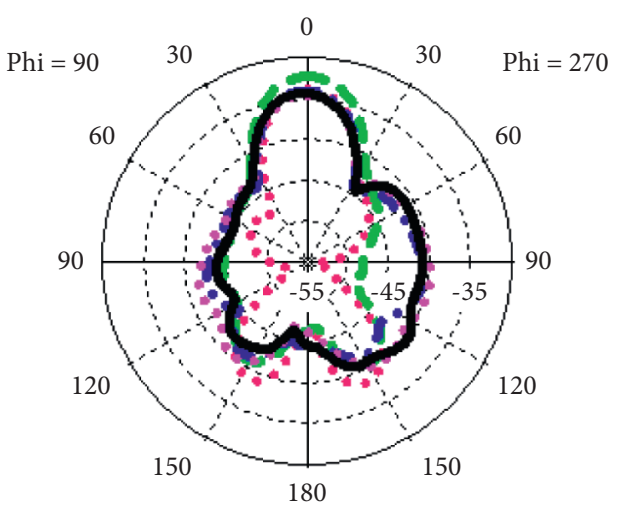

Theta/Degree vs. dBA/m

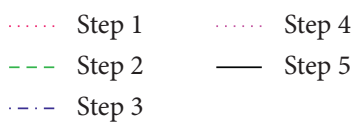

(d)

Farfield H-Field (r=1 m) Abs (Phi=90)

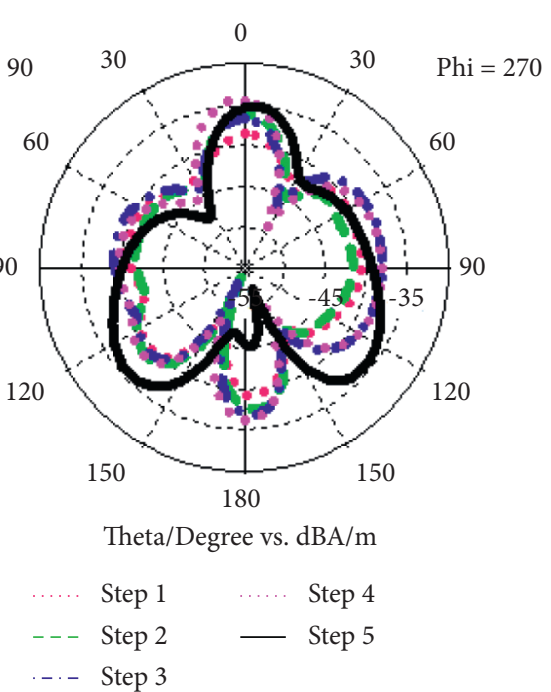

(f)

Figure 13: Magnetic field (H-field) for all the steps at Phi $=0^{\circ}$ and $90^{\circ}$ : (a) H-field (Phi $\left.=0^{\circ} ; 3.81 \mathrm{GHz}\right)$; (b) $\mathrm{H}$-field (Phi $=0^{\circ}$; $6.75 \mathrm{GHz}$; (c) $\mathrm{H}$ -

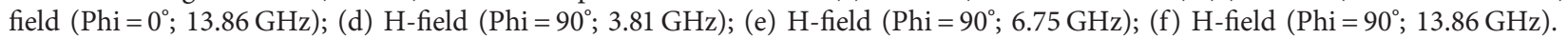


TABLe 3: Comparison with some recently published works.

\begin{tabular}{|c|c|c|c|c|}
\hline Ref. no. & Size $(L \times W \times h) \mathrm{mm}^{3}$ & Max. gain $(\mathrm{dBi})$ & BW (GHz) & Return loss $(\mathrm{dB})$ \\
\hline$[16]$ & $186 \times 77 \times 0.55$ & 16 & $2.5-57$ & - \\
\hline [17] & $62 \times 50.8 \times 0.8$ & 10 & $1.3-20$ & $\approx-33$ \\
\hline [18] & $100 \times 60 \times 0.008$ & 15 & $3-22$ & $\approx-45$ \\
\hline [19] & $60 \times 40 \times 0.508$ & 17.7 & $3.68-43.5$ & $\approx-43$ \\
\hline [20] & $100 \times 96 \times 0508$ & $2.2-11$ & $1-30$ & $\approx-35$ \\
\hline$[21]$ & $68 \times 52 \times 0.25$ & 14 & $6-18$ & $\approx-43$ \\
\hline [22] & $80 \times 44 \times 9.2$ & - & $2.4-18$ & $\approx-40$ \\
\hline [23] & $140 \times 66 \times 1.5$ & $\approx 10$ & $5-27$ & $\approx-25$ \\
\hline [24] & $70 \times 50 \times 1$ & 15 & $2.8-15$ & $\approx-31$ \\
\hline [25] & $66.5 \times 50 \times 1$ & 8.5 & $10-30$ & $\approx-50$ \\
\hline [26] & $36 \times 32 \times 2$ & 8 & $2.5-11$ & $\approx-40$ \\
\hline [27] & $31 \times 20 \times 0.51$ & 11 & $5.3-40$ & $\approx-25$ \\
\hline [28] & $200 \times 125 \times 1.2$ & 10.5 & $0.95-15.5$ & - \\
\hline Our designed & $45 \times 35 \times 0.79$ & 10.2 & $3.06-26.25$ & -40.32 \\
\hline
\end{tabular}

\section{Conclusion}

A super wideband Vivaldi antenna for lower $5 \mathrm{G}$ and satellite applications at C-, X-, Ku-, and $\mathrm{K}$-bands has been presented. Different strategies are applied to enhance the performance as well as to make it compact. It is achieved by etching ten opposite corrugated slots and two circular slots in the metallic flares. The material of substrate, radiating fins, cavity diameter, stub radius, stub angle etc. parameters are optimized to reduce the size of the antenna and to get better performance especially to get super wideband. Results show that the modified flares change electrical length and enhance the gain greater than $8 \mathrm{dBi}$, by adjusting the radius and angle of stub. There is an important effect of substrate material over the performance parameters, especially bandwidth and efficiency. The proposed Vivaldi antenna covers super wideband (3.06 GHz to $26.25 \mathrm{GHz}$ ), showing a returning loss of $-40.322 \mathrm{~dB}$, maximum gain of $10.2 \mathrm{dBi}$, VSWR of 1.07 , and average radiation efficiency of above 95\%. Given that, there are very good matching index during performance validation by the CST, FEKO, and HFSS. Therefore, the proposed design can be considered as an excellent model for the lower $5 \mathrm{G}$ and satellite applications.

\section{Data Availability}

The data used to support the findings of this study are included within the article.

\section{Conflicts of Interest}

The authors declare that they have no conflicts of interest.

\section{References}

[1] P. J. Gibson, "The vivaldi aerial," in Proceedings of the 9th European Microwave Conference, 1979, pp. 101-105, Brighton, UK, September 1979.

[2] D. H. Schaubert, "Endfire tapered slot antenna characteristics," in Proceedings of the 6th Int. Conf. Antennas and Propagation, vol. 2, pp. 432-436, Coventry, UK, April 1989.

[3] C. A. Balanis, Antenna: Analysis and Design, John Wiley and Sons, New Jersey, 3rd edition, 2005.
[4] R. Janaswamy and D. Schaubert, "Analysis of the tapered slot antenna," IEEE Transactions on Antennas and Propagation, vol. 35, no. 9, pp. 1058-1065, 1987.

[5] K. S. Yngvesson, D. H. Schaubert, E. L. kollberg, T. L. Korzeniowski, T. Thungren, and J. F. Johansson, "Endfire tapered slot antennas on dielectric substrates," IEEE Transactions on Antennas and Propagation, vol. 33, pp. 1392-1400, 1987.

[6] K. S. Yngvesson, T. L. Korzeniowski, Y.-S. Kim, E. L. Kollberg, and J. F. Johansson, "The tapered slot antenna-a new integrated element for millimeter-wave applications," IEEE Transactions on Microwave Theory and Techniques, vol. 37, no. 2, pp. 365-374, 1989.

[7] A. Naghar, "Ultra wideband and tri-band antennas for satellite applications at C-, X-, and Ku bands," in Proceedings of the 2014 IEEE Mediterranean Microwave Symposium, pp. 1-5, Marrakech, Morocco, December 2014.

[8] G. Ahmad, "A novel patch antenna design with slotted ground plane for satellite communications," Sindh University Research Journal (Science Series), vol. 49, no. 4, pp. 767-772, 2017.

[9] P. Kaur, K. Kaur, and K. Kaur, "Modification of Vivaldi tapered slot antenna with square shaped slot," International Journal of Engineering Trends and Technology, vol. 50, no. 4, pp. 230-233, 2017.

[10] M. Z. Mahmud, M. T. Islam, M. Samsuzzaman, S. Kibria, and N. Misran, "Design and parametric investigation of directional antenna for microwave imaging application," IET Microwaves, Antennas \& Propagation, 2016.

[11] L. C. Paul, M. N. Hossain, M. M. U. Rashid, M. M. Mowla, M. Z. Mahmud, and M. T. Islam, "A novel miniaturized coplanar waveguide fed tapered slot ultra wide band Vivaldi antenna for microwave imaging applications," in Proceedings of the IEEE 10th International Conference on Computing, Communication and Networking Technologies, pp. 1-6, Kanpur, India, July 2019.

[12] L. C. Paul, M. N. Hossain, M. M. Mowla, M. Z. Mahmud, R. Azim, and M. T. Islam, "Human brain tumor detection using CPW fed UWB Vivaldi antenna," in Proceedings of the 2019 IEEE International Conference on Biomedical Engineering, Computer and Information Technology for Health, pp. 1-6, Dhaka, Bangladesh, November 2019.

[13] D. Navarro, "Compact wideband Vivaldi monopole for LTE mobile communications," in Proceedings of the IEEE Antennas and Propagation Society International Symposium, pp. 1098-1099, Orlando, FL, USA, July 2013. 
[14] D. V. Navarro-Méndez, "Compact wideband Vivaldi monopole for LTE mobile communications," IEEE Antennas and Wireless Propagation Letters, vol. 14, pp. 1068-1071, 2015.

[15] Y. Dong, J. Choi, and T. Itoh, "Vivaldi antenna with pattern diversity for 0.7 to $2.7 \mathrm{GHz}$ cellular band Applications," IEEE Antennas and Wireless Propagation Letters, vol. 17, no. 2, pp. 247-250, 2018.

[16] J. Eichenberger, E. Yetisir, and N. Ghalichechian, "High-gain antipodal Vivaldi antenna with pseudoelement and notched tapered slot operating at (2.5 to 57) GHz," IEEE Transactions on Antennas and Propagation, vol. 67, no. 7, pp. 4357-4366, 2019.

[17] B. Biswas, R. Ghatak, and D. R. Poddar, "A fern fractal leaf inspired wideband Antipodal Vivaldi antenna for microwave imaging system," IEEE Transactions on Antennas and Propagation, vol. 65, no. 11, pp. 6126-6129, 2017.

[18] A. S. Arezoomand, R.-A. Sadeghzadeh, and M. Naser-Moghadasi, "Novel techniques in tapered slot antenna for linearity phase center and gain enhancement," IEEE Antennas and Wireless Propagation Letters, vol. 16, pp. 270-273, 2017.

[19] X. Li, H. Zhou, Z. Gao, H. Wang, and G. Lv, "Metamaterial slabs covered UWB antipodal Vivaldi antenna," IEEE Antennas and Wireless Propagation Letters, vol. 16, pp. 29432946, 2017.

[20] M. Moosazadeh, S. Kharkovsky, J. T. Case, and B. Samali, "Miniaturized UWB antipodal Vivaldi antenna and its application for detection of void inside concrete specimens," IEEE Antennas and Wireless Propagation Letters, vol. 16, pp. 1317-1320, 2017.

[21] L. Sang, S. Wu, G. Liu, J. Wang, and W. Huang, "High-gain UWB Vivaldi antenna loaded with reconfigurable 3-D phase Adjusting unit lens," IEEE Antennas and Wireless Propagation Letters, vol. 19, no. 2, pp. 322-326, 2020.

[22] J. Bourqui, M. Okoniewski, and E. C. Fear, "Balanced antipodal Vivaldi antenna with dielectric director for near-field microwave imaging," IEEE Transactions on Antennas and Propagation, vol. 58, no. 7, pp. 2318-2326, July 2010.

[23] I. T. Nassar and T. M. Weller, "A novel method for improving antipodal Vivaldi antenna performance," IEEE Transactions on Antennas and Propagation, vol. 63, no. 7, pp. 3321-3324, July 2015.

[24] Y.-W. Wang and Z.-W. Yu, "A novel symmetric double-slot structure for antipodal Vivaldi antenna to lower cross-polarization level," IEEE Transactions on Antennas and Propagation, vol. 65, no. 10, pp. 5599-5604, 2017.

[25] G. Teni, N. Zhang, J. Qiu, and P. Zhang, "Research on a novel miniaturized antipodal Vivaldi antenna with improved radiation," IEEE Antennas and Wireless Propagation Letters, vol. 12, pp. 417-420, 2013.

[26] D. Yang, S. Liu, and D. Geng, "A miniaturized ultra-wideband Vivaldi antenna with low cross polarization," IEEE Access, vol. 5, pp. 23352-23357, 2017.

[27] Z. Yin, G. He, X.-X. Yang, and S. Gao, "Miniaturized ultrawideband half-mode Vivaldi antenna based on mirror image theory," IEEE Antennas and Wireless Propagation Letters, vol. 19, no. 4, pp. 695-699, April 2020.

[28] P. Zhang and J. Li, "Compact UWB and low-RCS Vivaldi antenna using ultrathin microwave-absorbing materials," IEEE Antennas and Wireless Propagation Letters, vol. 16, pp. 1965-1968, 2017. 